
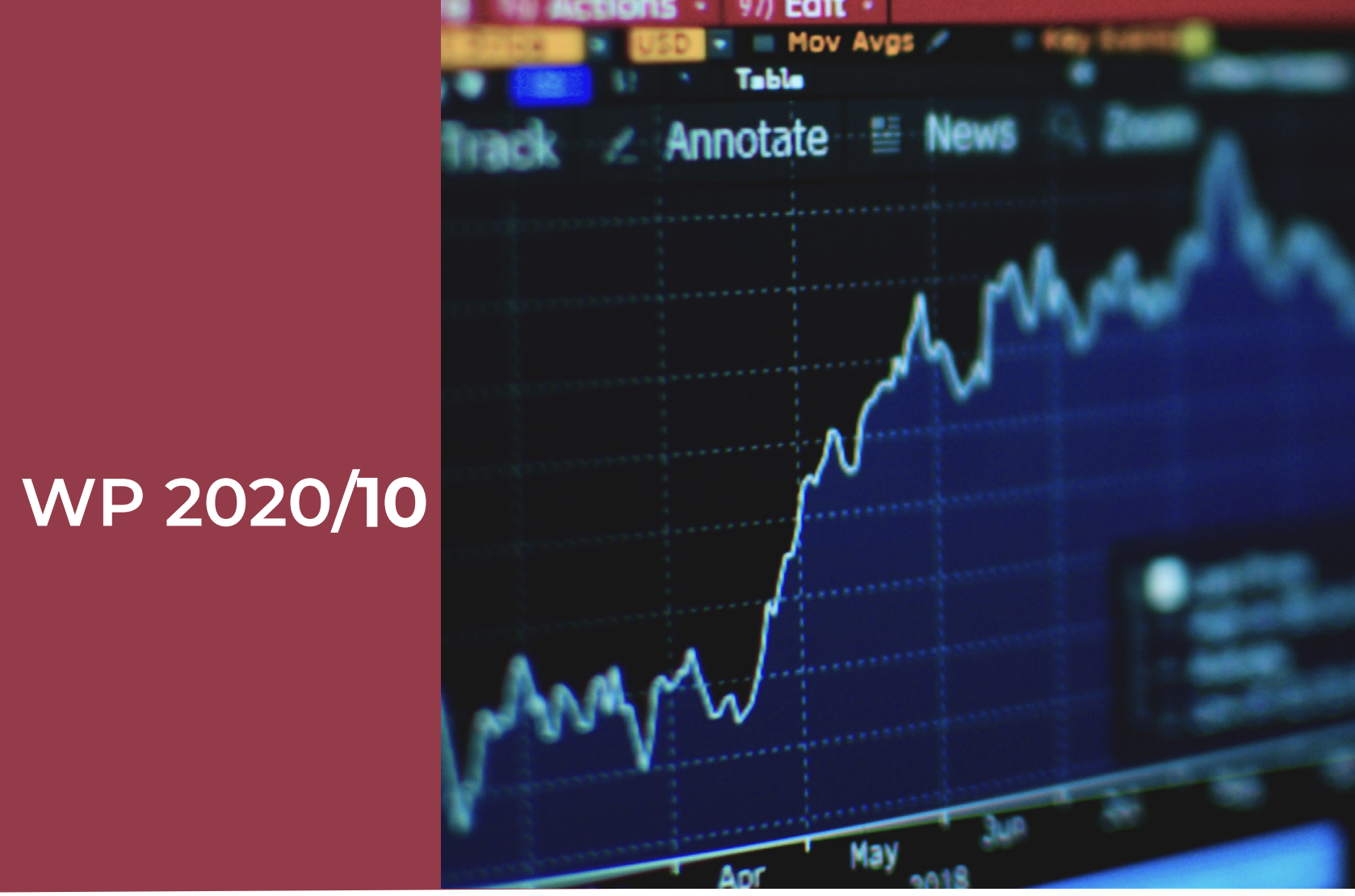

Leonardo Iania, Marco Lyrio and Rubens Moura

Bond Risk Premia in Emerging Markets:

Evidence from Brazil, China, Mexico, and Russia 


\section{LFIN}

Voie du Roman Pays 34, L1.03.01

B-1348 Louvain-la-Neuve

Tel (32 10) 474304

Email: lidam-library@uclouvain.be

https:/uclouvain.be/en/research-institutes/

lidam/lfin/working-papers.html 


\title{
Bond Risk Premia in Emerging Markets: Evidence from Brazil, China, Mexico, and Russia *
}

\author{
Leonardo Iania $^{\dagger} \quad$ Marco Lyrio ${ }^{\ddagger} \quad$ Rubens Moura ${ }^{\S}$
}

\begin{abstract}
We employ an affine term structure model with no-arbitrage restrictions and unspanned risk factors to analyse the global and domestic determinants of bond risk premia in four major emerging markets (Brazil, China, Mexico, and Russia). Among the risk factors, we select national inflation and economic growth, and the country-specific nominal exchange rate against the US dollar as the variables related to the domestic economy. We include a measure of worldwide economic activity, the Market Volatility Index (VIX), and an aggregate price index of commodities in the group of global factors. Our model captures (long-term) movements of realized risk premia and indicates that global economic and financial factors play a relevant role in explaining country-specific bond risk premia dynamics. In contrast, domestic variables carry little explanatory power to rationalize risk premia developments in these four economies. We also provide evidence of heterogeneous responses of country-specific risk premia to global and domestic shocks.
\end{abstract}

Keywords: Risk Premia, Term Structure of Interest Rates, International Finance, Emerging Markets.

JEL Classification: E43, E44, G15

${ }^{*}$ We are grateful to Bertrand Candelon, Anh Le, Sydney Ludvigson and Angelo Luisi for helpful comments over the development of this paper. All errors are ours.

${ }^{\dagger}$ CORE/LFIN, Université catholique de Louvain, Voie du Roman Pays 34, B-1348 Louvainla-Neuve, Belgium. Leonardo Iania acknowledges the financial support from the Fonds de la Recherche Scientifique-FNRS in Belgium (PDR T.0138.15 and EQP U.N006.18.) E-mail address: iania.leonardo@gmail.com.

¥DAO Capital, Head of Research, São Paulo, SP, Brazil. Marco Lyrio is grateful for financial support from the Conselho Nacional de Desenvolvimento Científico e Tecnológico in Brazil (Project No. 308310/2016-0); E-mail address: lyriomt@gmail.com.

${ }^{\S}$ Corresponding author. LFIN, Université catholique de Louvain, Voie du Roman Pays 34, B-1348 Louvain-la-Neuve, Belgium. E-mail address: rubens.guimaraes@uclouvain.be. 


\section{Introduction}

Emerging Markets (EM) economies have become a pivotal part of the world economy over the last decades. According to 2020 International Monetary Fund (IMF) world's economic outlook, South Africa, Indonesia, Brazil, Russia, India, China, Korea, Turkey, and Mexico (the largest EM economies) have grown, on average, by $4.6 \%$ a year over the last two decades, a growth rate that is 2.6 percentage points higher than advanced economies. ${ }^{1}$ This exceptional economic growth makes the largest EM economies account for around one third of the world's Gross Domestic Product (GDP) in 2017, according to the Organization for Economic Cooperation and Development (OECD).

The prodigious economic growth of EM economies has been mirrored by a relatively modest economic performance and falling interest rates in industrialized economies. Those developments have led international investors to shift their attention to high-yield instruments denominated in EM currencies, such as government bonds (see IMF (2019)). This trend, coupled with the increasing usage by EM countries of domestic government bonds to finance their activities, has amplified the size and importance of EM local currency debt. ${ }^{2}$ Against this background, understanding the drivers of government bond risk compensation (risk premium) in EMs is of primary importance for investors and policy makers. Investors need to have a clear view of the risk factors affecting their portfolio returns, while policy makers in EM governments are interested, for example, in assessing how national or international shocks affect their financing capacity.

Such concerns raise a number of questions. Are government bond risk premia in EM economies driven mainly by local or global factors? And do risk compensation in different EM economies react in a similar way to global shocks? We tackle these questions for four of the largest EM economies: Brazil, China, Mexico, and Russia, which together make 22\% of world's GDP in 2017, expressed in PPP. The selected countries exhibit significant differences in terms of size (measured by Gross Domestic Product), degree of economic openness and dependence on commodity exports. ${ }^{3}$

The quest for understanding the drivers of international bond risk premia

\footnotetext{
${ }^{1}$ This growth rate is the simple average of the yearly growth rates of South Africa, Indonesia, Brazil, Russia, India, China, Korea, Turkey, and Mexico from 2000 to 2019. If we weigh the yearly growth of those countries by their relative size, in terms of GDP, the average growth rate is around 6\%. Source: 2020 IMF world's economic outlook and Organization for Economic Cooperation and Development.

${ }^{2}$ In February 2020, S\&P Global estimates that the top 20 EMs are expected to issue a combined $\$ 1.62$ trillion of government debt in 2020, up 4\% from 2019 and a historical high; see https://www.spglobal.com/en/.

${ }^{3}$ According to the World Bank, in 2018,the trade-to-GDP ratios of Brazil, China, Mexico, and Russia were $29 \%, 38 \%, 80 \%$, and $51 \%$, respectively. Furthermore, Brazil and Russia are considered as export-commodity-dependent countries while China and Mexico are not. A country is considered to be export-commodity-dependent when more than 60 per cent of its total merchandise exports are composed of commodities (UNCTAD, 2019). Although there are interest rate databases for other emerging economies, their coverage in terms of time series length and maturity spectrum is rather limited. For this reason, we do not include India and possibly other EM countries in our sample.
} 
dates back to Ilmanen (1995), who finds that risk premia for long-maturity government bonds of six developed countries can be predicted by a small set of global instruments. In subsequent studies, scholars have explored the link between developed countries bond risk premia and different types of factors: (i) macroeconomic factors, in particular inflation uncertainty (see, for instance, Wright (2011)); (ii) factors based on a combination of forward rates, such as the Cochrane and Piazzesi (2005) factor ${ }^{4}$ (see Sekkel (2011) and Kessler and Scherer (2009)), or a world interest rate level factor as in Driessen et al. (2003); and (iii) global and local factors, where the global factor is linked to international business cycles, as in Dahlquist and Hasseltoft (2013).

Relative to developed economies, the literature on EM government bond risk premia is scant. Some scholars have focused their attention on the local and international drivers of EM government spreads. For example, Ciarlone et al. (2009) find that, in the pre-Lehman's period, large part of the co-variation in EM economies spreads is due to a single factor proxying for financial market volatility.

Recently, Cepni et al. (2019) and Cepni and Güney (2019) make several contributions adopting a panel setting. Cepni et al. (2019) highlight the combined importance of global and local factors in explaining bond risk premia, while Cepni and Güney (2019) find that the influence of local factors on bond risk premia can vary, among other aspects, with the level of risk aversion. Finally, the importance of global factors as drivers of EM bond risk premia is further stressed by the out-of-sample exercise proposed by Cepni et al. (2020).

In order to study the determinants of bond risk premia, we rely on affine term structure models, whereby bond yields are expressed as a linear function of pricing factors. These models specify the stochastic discount factor (pricing kernel) as function of a risk free rate and a set of shocks for which investors ask time-varying risk compensation. The latter feature is crucial for obtaining the time varying risk premia that are analyzed throughout the paper. We follow Joslin et al. (2011) and Joslin et al. (2014) and propose a no-arbitrage term structure model composed of two types of factors: $(i)$ spanned factors (or yield portfolios). These variables are formed as a linear combination of yields and are responsible for modelling the cross-sectional features of the yield curve; and (ii) unspanned factors. These factors contain macroeconomic and financial information that contribute to explain the dynamics of bond excess returns over and above the information contained in bond yields.

Our set of unspanned factors include a total of six local and global economic and financial factors: $(i)$ proxies for local economic activity and inflation, which are closely monitored by central banks; $(i i)$ the exchange rate, which is an important driver of local currency sovereign bond yields and risk premia in EM economies (see Gadanecz et al. (2018)); (iii) a proxy for global economic activity, which according to Dahlquist and Hasseltoft (2013) is closely linked

\footnotetext{
${ }^{4}$ The Cochrane and Piazzesi (2005) factor is obtained by regressing one-year excess returns across maturities at each time $t$ on five forward rates. They show that a tent-shaped linear combination of forward rates predicts annual excess returns on one- to five-year maturity bonds with $R^{2}$ up to 0.44 .
} 
to bond risk premia; ( $i v)$ changes in global commodity prices, which might increase the risk of higher inflation in emerging countries (Mallick, 2013); and $(v)$ the VIX index, which is an important driver of market prices of risk in EM government bonds (see Borri and Verdelhan (2011)). We investigate the relationship between each of these factors and the dynamics of bond risk premia through implied impulse response funcions (IRFs), variance decompositions and historical decompositions.

We contribute to this emerging literature in three ways. First, we show that arbitrage-free dynamic term structure models with local and global factors generate risk premia (model-implied expected excess returns) that replicate the realized excess returns with a correlation between the two series ranging from +0.83 (Brazil) to +0.65 (China). Second, through the lenses of our model, we assess the importance of local and global factors on risk premia dynamics. The results highlight the importance of global economic activity for Brazil and Russia, and of global commodity prices for China. The VIX index is also relevant in the case of Brazil and China. None of the global or domestic factors seem important in the determination of Mexico's bond risk premia. Finally, we provide evidence of heterogeneous responses of country-specific risk premia to global shocks. For example, only in the case of China positive global demand and commodity prices shocks lead to statistically significant increases in bond risk premia.

The remainder of the paper is organized as follows. Section 2 gives a brief overview of the evolution of affine term structure models and presents the framework adopted in this paper. We describe the yield curve data and each of the local and global unspanned factors in Section 3. The empirical results are presented in Section ??. We first assess the fit of the model for the yield curve and bond risk premia. We then discuss the IRFs, variance and historical decompositions of bond risk premia for each of the four EM countries analysed. Section 5 presents our conclusions.

\section{Econometrics framework}

We first describe the main characteristics of the affine class of term structure models applied to default-free zero-coupon bonds and summarize the main advantages of the approach proposed by Joslin et al. (2011) and Joslin et al. (2014). We then present the technical structure of the model showing the dependence of bond risk premia on both spanned and unspanned factors. We also discuss briefly the estimation procedure of the model.

\subsection{Affine yield curve models}

The affine class of term structure models was introduced by Duffie and Kan (1996). Such models rule out pure arbitrage opportunities and are both econometrically and numerically tractable. In this class of models, yields at all maturities are affine functions of the factors. This is due to the functional form 
assumed for the pricing kernel and the short-term interest rate. ${ }^{5}$

The factors in such models are, however, latent (unobservable) and do not have a direct economic meaning. A more satisfactory model should, therefore, also allow the identification of the economic forces behind movements in the yield curve and, as a consequence, in bond risk premia. Ang and Piazzesi (2003) pioneered such approach with the inclusion of macroeconomic variables as factors in the standard affine term structure model. ${ }^{6}$

Despite the widespread use of this approach, it presents one important drawback. In such models there is an implicit assumption that the macroeconomic factors can be expressed as a linear combination of bond yields, i.e. are spanned by bond yields. In other words, conditioning on the current yield curve, macroeconomic factors do not add information about their own future values and expected excess returns (bond risk premia). This assumption imposes counterfactual restrictions on the joint dynamics of bond yields and the macroeconomic factors and, moreover, is consistently rejected by standard regression analysis (Joslin et al., 2014).

In order to tackle this issue, Joslin et al. (2011) propose a normalization of affine models in which the pricing factors are observable portfolios of yields, i.e. linear combinations of yields. These are the spanned factors of the yield curve model. Joslin et al. (2014) complement this methodology and propose the introduction of macroeconomic variables as unspanned factors in otherwise standard affine models. ${ }^{7}$ Although the latter factors do not affect directly the shape of the yield curve, they may carry relevant information over and above the information contained in bond yields to forecast developments in the spanned factors and hence in excess bond returns. This methodology is suitable to assess the economic forces behind movements in bond risk premia and is, therefore, adopted in this paper to study the risk premium dynamics of EM government bonds.

\subsection{The model}

Following Joslin et al. (2014), we assume the existence of $K$ unobserved factors, $X_{t}$, which under the risk-neutral probability measure evolve according to a $\operatorname{VAR}(1)$ model:

$$
X_{t}=\mu_{X}^{Q}+\Phi_{X}^{Q} X_{t-1}+\Sigma_{X} \epsilon_{t}^{Q}, \quad \varepsilon_{t}^{Q} \sim N\left(0, I_{K}\right),
$$

\footnotetext{
${ }^{5}$ Dai and Singleton (2000) provide a complete characterization of the affine class of term structure models, specifying the conditions for admissibility and identification of such models.

${ }^{6}$ Other studies in this line of research include Bekaert et al. (2010), Dewachter and Lyrio (2006), Hördahl et al. (2006), and Rudebusch and Wu (2008), among others. In these papers, the factors either have a clear macroeconomic interpretation or are structural in nature. Gürkaynak and Wright (2012) and Piazzesi (2010) provide a detailed survey of this literature.

${ }^{7}$ This methodology has been used in different contexts by Bauer and Rudebusch (2020) and Dewachter et al. (2015), among others.
} 
where $\Sigma_{X}$ is lower-triangular and $\Phi_{X}^{Q}$ is diagonal with distinct entries. Assuming the short-term rate $r_{t}$ is affine on $X_{t}$,

$$
r_{t}=\delta_{0}+\delta_{1} X_{t}
$$

Dai and Singleton (2000) show that the price of a zero coupon bond is given by:

$$
P_{t}^{(n)}=E_{t}^{Q}\left[e^{\sum_{j=0}^{n-1}\left(-r_{j+1}\right)}\right]=E_{t}^{Q}\left[e^{\mathrm{a}^{(n)}+\mathrm{b}^{(n)} X_{t}}\right],
$$

where $\mathbf{a}^{(n)}$ and $\mathbf{b}^{(n)}$ solve the well-known Riccati difference equations: ${ }^{8}$

$$
\begin{gathered}
\mathrm{a}^{(n)}=\mathrm{a}^{(n-1)}+\mathrm{b}^{(n-1)} \Phi_{X}^{Q}+\frac{1}{2} \mathrm{~b}^{(n-1)} \Sigma_{X} \Sigma_{X}^{\prime} \mathrm{b}^{(n-1)^{\prime}}-\delta_{0} \\
\mathbf{b}^{(n)}=\mathrm{b}^{(n-1)} \Phi_{X}^{Q}-\delta_{1},
\end{gathered}
$$

with initial conditions: $\mathrm{a}^{(0)}=0$ and $\mathrm{b}^{(0)}=\mathbf{0}$. To obtain the loadings for the corresponding yield, we observe that the log of the bond price is $p_{t}^{(n)}=-n y_{t}^{(n)}$, hence:

$$
y_{t}^{(n)}=-\frac{1}{n} \mathrm{a}^{(n)}-\frac{1}{n} \mathrm{~b}^{(n)} X_{t}=a^{(n)}+b^{(n)} X_{t},
$$

Assuming a total of $N$ maturities, we can express Eq. (6) as

$$
Y_{t}=A+B X_{t}
$$

with $Y_{t}=\left[y_{t}^{(1)}, \ldots, y_{t}^{(N)}\right]^{\prime}$. Joslin et al. (2011) show that $X_{t}$ can be rotated and linked to a set of spanned yield curve factors, $P_{t}=W Y_{t}$, with $W$ being a full-rank matrix, leading to the following representation of the yield curve:

$$
Y_{t}=A_{P}+B_{P} P_{t},
$$

with $A_{P}=I-B(W B)^{-1} W A$ and $B_{P}=B(W B)^{-1}$. Under the historical probability measure, spanned factors are related to $U$ unspanned factors, $M_{t}$, via a $\operatorname{VAR}(1)$ model. Stacking $P_{t}$ and $M_{t}$ in a vector $Z_{t}=\left[M_{t} ; P_{t}\right]$, we have that

$$
Z_{t}=C^{\mathbb{P}}+\Phi^{\mathbb{P}} Z_{t-1}+\Sigma \varepsilon_{Z, t}^{\mathbb{P}}
$$

where $\varepsilon_{Z, t}^{\mathbb{P}}=\left(\varepsilon_{M, t}^{\mathbb{P}}, \varepsilon_{P, t}^{\mathbb{P}}\right)^{\prime} \sim N(0, I)$ and $\Sigma$ is a lower-triangular matrix. Equation (9) implies that the $h$-period expected value of $Z_{t}$ (and hence of $P_{t}$ and $\left.Y_{t}\right), \mathbb{E}_{t} Z_{t+h}$, is a function of both $P_{t}$ and $M_{t}$. is

The $h$-period risk premium of a zero-coupon bond with maturity $n, r x_{t}^{(n, h)}$,

$$
r x_{t}^{(n, h)}=\left(\mathbb{E}_{t}\left[p_{t+h}^{(n-h)}\right]-p_{t}^{(n)}\right)-y_{t}^{(h)},
$$

where $p_{t}^{(n)}=-n y_{t}^{(n)}$ is the $\log$ of the bond price. Iterating forward Eq. (9) and given Eq. (7), we can express Eq. (10) as:

$$
r x_{t}^{(n, h)}=A_{r x}^{(n)}+B_{r x}^{(n)} Z_{t}
$$

\footnotetext{
${ }^{8}$ See Ang and Piazzesi (2003) for a detailed derivation.
} 
with

$$
\begin{gathered}
A_{r x}^{(n)}=n A_{Z}^{(n)}-A_{Z}^{(h)}-(n-h) \sum_{j=0}^{h-1}\left(\Phi^{\mathbb{P}}\right)^{j} C^{\mathbb{P}}, \\
B_{r x}^{(n, h)}=n B_{Z}^{(n)}-(n-h) B_{Z}^{(n-h)}\left(\Phi^{\mathbb{P}}\right)^{h}-B_{Z}^{(h)},
\end{gathered}
$$

where $A_{Z}^{(n)}=A_{P}^{(n)}$, and $B_{Z}^{(n)}=\left[B_{P}^{(n)} \mathbf{0}\right]$, with the zero vector is of dimension $U$. Given that $\Phi^{\mathbb{P}}$ is a full matrix, Eqs. (12) and (13) imply that bond risk premia are a function of both spanned and unspanned factors.

We estimate the model in two steps. First, we obtain estimates of $C^{\mathbb{P}}$ and $\Phi^{\mathbb{P}}$ via OLS (Eq. (9)). Subsequently, the remaining parameters, $\Phi_{X}^{Q}, \delta_{0}$, and $\Sigma$, are estimated using maximum likelihood. We then obtain the confidence bands on (function of) parameters of interest by wild bootstrapping the residuals of the model. For econometric identification, we assume that $\mu_{X}^{Q}=0$, allowing us to interpret $\delta_{0}$ as the long-run mean of the short rate under the $\mathbb{Q}$-measure. We also choose $\delta_{1}$ to be a $K$-dimensional row vector, all elements of which are one. Finally, we assume that under the risk-neutral probability measure the yield's portfolios follow a stationary VAR. This specification is necessary to avoid that yields diverge to minus infinity with maturity. ${ }^{9}$

\section{Data}

Our analysis covers the period from September 2005 to September 2017 and is composed of three sets of series: $(i)$ the countries' term structures of interest rates; (ii) local macroeconomic factors; and (iii) global economic and financial factors. For each country's term structure, we use end-of-the-month zero-coupon yields with maturities of $1,6,12,36,60$, and 120 months. For China, Mexico, and Russia the data are from Bloomberg. ${ }^{10}$ For Brazil, due to longer data availability, we select the yields on swap fixed-DI contracts ${ }^{11}$ retrieved from $B^{3}$, the Brazilian Stock Exchange and Over-the-Counter Market. All the yields refer to local currency-denominated contracts.

As local macroeconomic factors, we include proxies for inflation and local economic activity, which are closely monitored by central banks, and the nominal exchange rate, which is an important driver of local currency sovereign bond yields and risk premia in EM economies; see Gadanecz et al. (2018). Specifically, $(i)$ a proxy for inflation $\left(\pi_{t}^{j}\right)$ is computed as the yearly growth rate of the Consumer Price Index (CPI) of country $j$ and obtained from the IMF, (ii) a proxy for domestic economic activity $\left(g_{t}^{j}\right)$ is obtained as the normalized country-specific leading indicator for the Gross Domestic Product (GDP), which

\footnotetext{
${ }^{9}$ See Bauer and Rudebusch (2020).

${ }^{10}$ Since the Bloomberg data are for par yields, we bootstrap the original data to obtain zerocoupon yields. The 1-month yield for Russia, Mexico and China are obtained by estimating and fitting a Nelson-Siegel model.

${ }^{11}$ These are derivative instruments with the underlying values linked to Brazil's interbank lending rate. For a detailed explanation regarding the use of such instruments, see Vicente and Tabak (2008) and Shousha (2011).
} 
is developed by the OECD and retrieved from the FRED, the Federal Reserve Bank of St. Louis, and (iii) the nominal exchange rate $\left(s_{t}^{j}\right)$ is expressed as the price of one US dollar in terms of the local currency, also from the IMF.

We also include three global factors: $(i)$ a proxy for real global economic activity $\left(g_{t}^{W}\right)$, which accounts for the relationship between risk premia and global economic activity, as suggested by Dahlquist and Hasseltoft (2013). This factor is captured by Lutz Kilian's measure (Kilian, 2009), available at his webpage; (ii) a proxy for changes in global commodity prices $\left(\pi_{t}^{W}\right)$, which might increase the risk of higher inflation in emerging countries (see Mallick (2013)). This measure is given by the yearly growth of the global commodity price index; and (iii) a proxy for global financial market tensions $\left(V I X_{t}\right)$, which is an important driver of market prices of risk in EM government bonds; see Borri and Verdelhan (2011) and Zinna (2013). This proxy is represented by the Chicago Board Options Exchange (CBOE) Market Volatility (VIX) Index. We obtain the last two factors from the FRED website. The choice of $\pi_{t}^{W}$ and $V I X_{t}$ as global factors is also motivated by Ciarlone et al. (2009). They extract a common factor capturing the variability of emerging market sovereign spreads which is not directly linked to the specific macroeconomic characteristics of any given

country. This factor correlates strongly with the VIX index and the growth of commodities prices.

For each country $j$, our model includes two spanned, $P_{t}^{j}$, and six unspanned factors, $M_{t}^{j}$. The spanned factors are the the first two principal components (PCs) of the country's bond yields. The unspanned factors are the countryspecific and global factors listed above. We use a Cholesky identification scheme, whereby variables are ordered from the most exogenous (international factors, i.e. $g^{W}, \pi^{W}$, and $V I X$ ) to the least exogenous (national factors, i.e. $s, \pi$, and $g)$ :

$$
M_{t}^{j}=\left[g_{t}^{W}, \pi_{t}^{W}, V I X_{t}, s_{t}^{j}, \pi_{t}^{j}, g_{t}^{j}\right]^{\prime} ; \quad P_{t}^{j}=\left[P C 1_{t}^{j}, P C 2_{t}^{j}\right]^{\prime} .
$$

Figure 1 shows the time series of all unspanned and spanned factors. The first row of subplots shows the unspanned international factors. We observe clearly a downward trend in global economic activity since its peak in May 2008 during the global financial crisis. We also see that the VIX index reached its peak in November 2008 and global commodity prices hit its lowest level in July 2009. The second and third rows of subplots depict the unspanned national factors and the spanned factors for each country, respectively.

Insert Figure 1 here

Tables 1 and 2 report a summary statistics of our set of local (Table 1) and global (Table 2) factors together with the one-year realized excess returns for the 3 - and 10-year bonds for each country. For each variable, we present the 
first four moments and the autocorrelations at 1 and 12 lags. We also present the correlation matrices for the factors and realized excess returns. For the correlation matrices, the numbers in bold are statistically significant at a $95 \%$ confidence level.

\section{Insert Tables 1 and 2 here}

Focusing on the correlation matrices for each country, two general patterns emerge. First, while within country realized excess returns are highly correlated (the lowest correlation is +0.71 for the Mexican bonds), Table 2 indicates that the correlations among the realized excess returns across countries are characterized by a high degree of heterogeneity. Correlations range from -0.43 between the 10-year Russian bond $\left(e r_{R}^{10,1}\right)$ and the 3 -year Chinese bond $\left(e r_{C}^{3,1}\right)$ to +0.42 between the 10-year Brazilian $\left(e r_{B}^{10,1}\right)$ and Mexican $\left(e r_{M}^{10,1}\right)$ bonds. Furthermore, the Brazilian realized excess returns seem to be disconnected from the Chinese and Russian counterparts (correlations are not statistically different from zero).

The second pattern is in line with the previous point. The correlations between local/global factors and realized excess returns are heterogeneous across countries. For example, we notice that realized excess returns on Chinese and Mexican (3-year maturity) bonds are positively correlated with global economic activity, while this correlation is negative for Russian bonds and insignificant for Brazilian ones. A similar heterogeneous pattern emerges if we consider local economic activity. The correlation between local economic activity and realized excess return is negative for all countries except China. Both patterns are in line with the extant evidence on realized excess return dynamics, i.e. realized excess return among maturities are highly correlated and tend to be countercyclical, see e.g. Cochrane and Piazzesi (2005) and Ludvigson and Ng (2009)), among others.

\section{Results}

In Section 4.1, we assess the fit of model-implied bond yields and risk premia. In the subsequent sections, we examine how shocks to each of the unspanned factors influence our estimates of bond risk premia. To this end, we analyse IRFs (Section 4.2), variance decompositions (Section 4.3), and historical decompositions (Section 4.4).

\subsection{Fit of bond yields and risk premia}

The model delivers a very good fit of the yield curve in each of the four countries. The coefficients of determination $\left(R^{2}\right)$ of model-implied bond yields in fitting realized bond yields are in all cases above 0.95 , as reported in Table 3 . As an illustration, Fig. 2 shows the model fit for the 3 - and 10-year bond yields. As 
can be seen, throughout the sample period, the error terms are close to zero. As such results are standard in the literature, we focus our attention on the fit of bond risk premia.

\author{
Insert Table 3 here \\ Insert Figure 2 here
}

The statistics for the model-implied one-year bond risk premia ${ }^{12}$ is summarized in Table 4. Figure 3 also plots the risk premia on a 3 - and 10-year bond against the realized excess returns. In each subplot, the realized excess return (black dotted line) ends 12 months before the end of our sample period. This is the case since the realized excess return is computed based on data at $t+12$ months. The risk premium (blue solid line), however, can be computed until the end of the sample period.

From Table 4, we observe that for all countries both the mean $(\mu)$ and standard deviation $(\sigma)$ of the risk premia increase with maturity. The largest risk premia on average are from Brazil and Mexico and the most volatile from Brazil and Russia.

\title{
Insert Figure 3 here \\ Insert Table 4 here
}

Figure 3 shows that bond risk premia are in line with realized excess returns, despite the higher volatility of the latter. Table 4 reports the ratio between the standard deviation of bond risk premia and the standard deviation of realized excess returns $\left(\sigma^{R P} / \sigma^{e r}\right)$. For all countries, this ratio is below 1 and decreases with maturity, i.e. realized excess returns have a higher volatility in comparison with bond risk premia for longer maturity bonds. Across countries, this ratio ranges from 0.87 (Mexico, 36-month bond) to 0.52 (China, 120-month bond).

Although realized excess returns are more volatile than bond risk premia, our model captures the low frequency movements of such returns. The correlation between these two series for all countries and bond maturities ranges from +0.65 to +0.83 (see Table 4). We believe this is a striking result. As mentioned before, realized excess returns are obtained using information at time $t+12$ months, while model-implied risk premia are obtained using information available at time $t$ and via restricted coefficients derived from no-arbitrage conditions (see Eq. (11)).

Finally, in all cases except Brazil the correlation between risk premia and realized excess returns (or equivalently the coefficient of determination, $R^{2}$ ) decreases with maturity. This is to be expected due to the pattern exhibited

${ }^{12}$ This means the risk premium computed with a holding period of one year. 
by the ratio $\sigma^{R P} / \sigma^{e r}$ mentioned above. In other words, when the volatility of realized excess returns is higher in comparison with that of bond risk premia, the model's performance in fitting the realized excess returns is lower. Interestingly, this does not happen in the case of Brazil, where despite a higher volatility of realized excess returns for long-term bonds the model's performance increases with maturity.

Having analysed the statistics of bond risk premia, we now investigate how shocks to each of the unspanned factors in our model propagate in time throughout bond risk premia.

\subsection{Impulse response functions}

In this section, we examine the responses of bond risk premia to shocks impacting each of the six unspanned factors in the model. Figure 4 plots the median response of the one-year risk premium on a 10-year maturity bond to a one standard deviation positive shock in each of the factors. This figure also shows the confidence intervals obtained from a bootstrap procedure and constructed for a level of significance equal to $66 \%$. The horizontal axis is given in months and the risk premium responses (vertical axis) are given in level per annum. We show the impulse responses up to an impact period of 24 months.

Insert Figure 4 here

The IRFs are computed based on a Cholesky decomposition with the ordering of the variables defined in Eq. 14. The same ordering (from left to right) is used in each row of subplots for each country.

In line with intuition, positive shocks to global economic activity $\left(g^{W}\right)$ induce an instantaneous reduction in the bond risk premium in Brazil and Mexico (marginally). These responses are, however, not statistically significant. In the case of Russia, this response is negative and statistically significant between six and nine months. On the contrary, for Brazil, this response becomes positive and statistically significant between two and ten months. And, for Mexico, the same happens after about 21 months. For China, the instantaneous effect is positive being statistically significant up to about nine months. Long-term positive responses of bond risk premium to economic growth are counter-intuitive but in line with the results of Abbritti et al. (2018) for a number of countries.

Positive global commodity price $\left(\pi^{W}\right)$ shocks trigger a statistically significant increase in the Chinese bond risk premium of around 90 basis points. The response of China to shocks on $\pi^{W}$ (and $g^{W}$ ) might be linked to possible fears of internal inflationary pressure following those global shocks. Furthermore, unlike other emerging economies, China is a large commodity importer and not exporter (UNCTAD, 2019). Hence, an increase in risk-premium is expected. Brazil and Mexico also show a positive response but not statistically significant. The opposite effect is observed for Russia, where positive shocks to $\pi^{W}$ decrease 
the required compensation for risk. Although this response is not statistically significant, it is probably due to the country's heavy reliance on commodity exports. As a matter of fact, a large body of literature documents that the international prices of commodities have nontrivial macroeconomic implications for developing economies; see Fernández et al. (2018).

A positive shock to the VIX index causes an increase in the bond risk premium in all countries. This response is statistically significant in the cases of Brazil and Russia. For Brazil, the risk premium increases by around 3\%, while for Russia it peaks after about six months. These results point to a higher sensitivity of those two bond markets to global financial market turbulence.

An exchange rate $(s)$ devaluation shock drives risk premium up in all countries. The initial increase is statistically significant for Brazil and Russia, where it increases by $3 \%$ and almost $4 \%$, respectively. Intuitively, as part of a country's liabilities is denominated in foreign currency, a weakening of the domestic currency increases the total debt burden. This positive increment in the debt service might lead investors to require an extra compensation for holding domestic assets.

In line with the findings of Wright (2011), inflation $(\pi)$ shocks increase bond risk premium for all countries in a statistically significant way. The highest impact is observed for Brazil where it reaches a maximum of 200 basis points after about three months. The reaction of China's risk premium is statistically significant on impact but with the lowest value among the four countries, about 25 basis points. Mexico and Russia exhibit a maximum of 50 and 90 basis points after about 15 and 11 months, respectively. This indicates that following inflationary pressures investors require a positive risk premium to hold nominal bonds of long maturities.

Finally, as expected, a positive shock to the local economic activity factor $(g)$ triggers, in general, a negative response of the risk premium on impact in all countries. Russia is the most prominent case with a decrease in the risk premium of about 30 basis points being statistically significant until almost one year. For Brazil, the negative effect is significant around 4 months but positive and significant after one year. Although the Chinese risk premium decreases on impact it only becomes significant after six months when is then positive. Finally, the effect on Mexico's risk premium is not significant.

The responses of the risk premium on bonds of other maturities are qualitatively very similar. In the Appendix (Fig. 6), as an illustration, we present the response of the one-year risk premium on a 3-year maturity bond.

\subsection{Variance decompositions}

We now perform a variance decomposition exercise in order to identify the main drivers behind movements in bond risk premia. This technique allows us to estimate the proportion of risk premium movements attributable to each factor (unspanned and spanned). Table 5 shows the variance decomposition of the one-year risk premium on a 10-year bond. We list the contribution of each factor to the forecast variance for a horizon of 1, 12, 60, and 120 months ahead. 
Each row in the table adds up to $100 \%$. The ordering of the variables is the same as the one used for the IRFs.

Insert Table 5 here

Table 5 shows that, in all cases except Russia, the proportion of forecast variance accounted for by the six unspanned factors increases with the forecasting horizon. Global economic activity is the most important unspanned factor driving movements in bond risk premia for all countries except China. This factor is especially important for Brazil, having a consistent impact across all horizons. In the case of China, global commodity prices has the largest effect on risk premia. This factor is also relevant for Russia. The VIX index, the exchange rate, and inflation also have a significant influence in the forecast variance of risk premia for Brazil and Russia. Interestingly, domestic economic activity seems to have very little impact on bond risk premia for all countries.

For Mexico, the spanned factors account for most of the forecast variance for all forecasting horizons ( $89 \%$ for one-month ahead to $51 \%$ for a ten-year horizon). In the case of China, latent factors dominate the forecast variance for short horizons ( 1 and 12 months) but macro and financial factors slightly dominate medium to long horizons. Among those, global commodity prices stand out for having an important contribution (around 20\%) at all horizons.

For Brazil and Russia, the unspanned factors are responsible for most of the forecast variance at all forecasting horizons, reaching $85 \%$ in the case of Brazil for a 10-year horizon. With respect to Brazil, global economic activity is overall the most important factor driving movements in bond risk premia. The VIX index and the exchange rate also play a significant role in the short horizon, while domestic inflation appears relevant for longer horizons. For Russia, the exchange rate and global commodity price shocks dominate at a short horizon, while global economic activity is predominant at long horizons.

In the Appendix (Table 6), we present the variance decomposition of the one-year risk premium on a 3-year bond. The qualitative results are mostly the same. One main difference is the presence of inflation instead of global commodity prices as the most important unspanned factor in the case of China.

\subsection{Historical decompositions}

The variance decomposition discussed above highlighted the importance of specific factors for each country. In order to visualize the contribution over time of each of those factors, we perform a historical decomposition of the one-year risk premium on a 10-year bond for each country over our sample period. Each column in Fig. 5 shows the contribution of each unspanned factor for a particular country. The dotted line in each subplot shows the total risk premium over time and the solid line the contribution of the factor under consideration. We focus our discussion on the main spikes of the risk premium in each country. 
Insert Figure 5 here

For Brazil, we analyse two spikes. The first one occurred in October 2008, at the end of the global financial crisis. Not surprisingly, the sharp increase in the risk premium is mainly driven by variables external to the country. Global economic activity and the VIX index represent $37 \%$ and $27 \%$ of the absolute contribution to the total bond risk premium in that period. The second spike occurred at the beginning of 2016 (January). During this period, Brazil experienced a deep economic recession combined with high inflation and a depreciated domestic currency (see also Fig. 1). The exchange rate reached its weakest level against the dollar during that period. Global commodity prices were also still recovering from its bottom value in August 2015. As a consequence, we find that domestic inflation, global commodity prices, and the exchange rate are responsible for a substantial part of the bond risk premium (above $50 \%$ in absolute terms).

In the case of China, we focus on the main spike in the 10-year risk premium occurred in July 2008, also during the global financial crisis. Global commodity prices were almost at its peak, reached in June 2008 (see Fig. 1). The increase in the risk premium during this period, therefore, can be largely attributed $(30 \%)$ to the high level of commodity prices in the world market. Global economic activity is also responsible for a substantial part (around 20\%) of the risk premium.

With respect to Mexico, our historical decomposition shows the predominant contribution of latent factors. This can also be seen in the three spikes observed in the risk premium during our sample period. In the first spike (May 2006), we observe some contribution of global commodity prices and the VIX index (less than 10\% each in absolute terms). Around the second spike (Oct 2009), at the end of the global financial crisis, global economic activity and global commodity prices play significant roles. In the third spike (Feb 2011), we observe a significant contribution ( $20 \%$ in absolute terms) from the global economic activity.

Finally, for Russia, we focus on the spike of July 2009. Local economic activity is responsible for a significant part of the 10-year bond risk premium (close to $30 \%$ in absolute terms) during this period. The VIX index and global commodity prices also have a significant impact on bond risk premium (almost $40 \%$ jointly in absolute terms).

The historical decomposition of the risk premium for bonds with other maturities provide qualitatively similar results. As an illustration, Fig. 7 in the Appendix shows the one-year risk premium on a 3-year bond for the countries in our sample. 


\section{Conclusions}

The increasing importance of EM economies as a source of global economic growth calls for an understanding of the dynamics of local government debt market. This market is a major source of financing for local governments and offers to international investors financial instruments with relatively high returns. Understanding the dynamics of these markets is hence pivotal.

We examine the importance of global and local factors in the determination of bond risk premia in major EM economies, i.e. Brazil, China, Mexico, and Russia. Global economic and financial factors are key drivers of movements in risk premia. Global economic activity, financial tension and the exchange rate play a significant role for Brazil and Russia. Global commodity prices influence Russian bond risk premia and are a leading factor for Chinese ones. The Mexican bond market seems more resilient to global and financial shocks.

Policy makers and investors might benefit from our results. For investors, the diverse reaction of local risk premia to global shocks might create potential diversification opportunities. For policy-makers, our results show that, depending on the shock, some large countries might require closer monitoring than others.

Our results open up new avenues of research. Two are the following: First, in this paper we model each bond market separately. It would be interesting to develop a model that jointly prices government bonds of different emerging countries by means of global and local factors. The advantage of such a model would be that one can potentially analyse spillover effects among countries. Second, in this paper we look at one aspect of government bond markets, i.e. risk premia. However, it would be interesting to look at more policy-related measures such as the expected evolution of short-term rates and term premia. These lines of research will be the topic of future work.

\section{References}

Abbritti, M., S. Dell'Erba, A. Moreno, and S. Sola (2018). Global factors in the term structure of interest rates. International Journal of Central Banking 14(2), 301-339.

Ang, A. and M. Piazzesi (2003). A no-arbitrage vector autoregression of term structure dynamics with macroeconomic and latent variables. Journal of Monetary Economics 50(4), 745-787.

Bauer, M. D. and G. D. Rudebusch (2020). Interest rates under falling stars. American Economic Review 110(5), 1316-54.

Bekaert, G., S. Cho, and A. Moreno (2010). New-Keynesian macroeconomics and the term structure. Journal of Money, Credit and Banking 42(1), 33-62.

Borri, N. and A. Verdelhan (2011). Sovereign risk premia. AFA 2010 Atlanta Meetings Paper. 
Cepni, O., S. Gul, and R. Gupta (2019). Local currency bond risk premia of emerging markets: The role of local and global factors. Finance Research Letters, forthcoming.

Cepni, O. and I. Güney (2019). Local currency bond risk premia: A panel evidence on emerging markets. Emerging Markets Review 38, 182 - 196.

Cepni, O., R. Gupta, I. E. Güney, and M. Yilmaz (2020). Forecasting local currency bond risk premia of emerging markets: The role of cross-country macrofinancial linkages. Journal of Forecasting, forthcoming.

Ciarlone, A., P. Piselli, and G. Trebeschi (2009). Emerging markets' spreads and global financial conditions. Journal of International Financial Markets, Institutions and Money 19(2), 222 - 239.

Cochrane, J. H. and M. Piazzesi (2005). Bond risk premia. American Economic Review 95(1), 138-160.

Dahlquist, M. and H. Hasseltoft (2013). International bond risk premia. Journal of International Economics 90(1), 17-32.

Dai, Q. and K. J. Singleton (2000). Specification analysis of affine term structure models. The Journal of Finance 55(5), 1943-1978.

Dewachter, H., L. Iania, M. Lyrio, and M. de Sola Perea (2015). A macrofinancial analysis of the euro area sovereign bond market. Journal of Banking and Finance 50, 308-325.

Dewachter, H. and M. Lyrio (2006). Macro factors and the term structure of interest rates. Journal of Money, Credit and Banking 38(1), 119-140.

Driessen, J., B. Melenberg, and T. Nijman (2003). Common factors in international bond returns. Journal of International Money and Finance 22(5), 629-656.

Duffie, D. and R. Kan (1996). A yield-factor model of interest rates. Mathematical Finance 6(4), 379-406.

Fernández, A., A. Gonzalés, and D. Rodriguez (2018). Sharing a ride on the commodities roller coaster: Common factors in business cycles of emerging economies. Journal of International Economics 111, 99-121.

Gadanecz, B., K. Miyajima, and C. Shu (2018). Emerging market local currency sovereign bond yields: The role of exchange rate risk. International Review of Economics \& Finance 57, 371 - 401.

Gürkaynak, R. S. and J. H. Wright (2012). Macroeconomics and the term structure. Journal of Economic Literature 50(2), 331-367. 
Hördahl, P., O. Tristani, and D. Vestin (2006). A joint econometric model of macroeconomic and term-structure dynamics. Journal of Econometrics 131(1-2), 405-444.

Ilmanen, A. (1995). Time-varying expected returns in international bond markets. The Journal of Finance 50(2), 481-506.

IMF (2019). Emerging and frontier markets: Mind the debt. Global Financial Stability Report, October, IMF.

Joslin, S., M. Priebsch, and K. J. Singleton (2014). Risk premiums in dynamic term structure models with unspanned macro risks. The Journal of Finance 69(3), 1197-1233.

Joslin, S., K. J. Singleton, and H. Zhu (2011). A new perspective on Gaussian dynamic term structure models. The Review of Financial Studies 24(3), 926970.

Kessler, S. and B. Scherer (2009). Varying risk premia in international bond markets. Journal of Banking \& Finance 33(8), 1361-1375.

Kilian, L. (2009). Not all oil price shocks are alike: Disentangling demand and supply shocks in the crude oil market. The American Economic Review 99(3), 1053-1069.

Ludvigson, S. C. and S. Ng (2009). Macro factors in bond risk premia. Review of Financial Studies 22(12), 5027-5067.

Mallick, S.K., S. R. (2013). Commodity prices, inflationary pressures, and monetary policy: Evidence from BRICS economies. Open Economies Review 24(4), 677-694.

Piazzesi, M. (2010). Affine term structure models. In Y. Ait-Sahalia and L. P. Hansen (Eds.), Handbook of Financial Econometrics: Tools and Techniques, Volume 1, Chapter 12, pp. 691-766. Elsevier/North-Holland.

Rudebusch, G. D. and T. Wu (2008). A macro-finance model of the term structure, monetary policy and the economy. The Economic Journal 118, 906-926.

Sekkel, R. (2011). International evidence on bond risk premia. Journal of Banking 85 Finance 35(1), $174-181$.

Shousha, S. (2011). Macroeconomic dynamics and the term structure of interest rates in emerging markets: The Brazilian case. In J. Batten, P. G. Szilagyi, R. Thornton, and J. R. Aronson (Eds.), The Impact of the Global Financial Crisis on Emerging Financial Markets, Volume 93, Chapter 18, pp. 547-579. Emerald Group Publishing Limited.

UNCTAD (2019). State of commodity dependence. Technical report, United Nations Conference on Trade and Development. 
Vicente, J. and B. M. Tabak (2008). Forecasting bond yields in the Brazilian fixed income market. International Journal of Forecasting 24(3), 490 - 497.

Wright, J. H. (2011). Term premia and inflation uncertainty: Empirical evidence from an international panel dataset. American Economic Review 101(4), $1514-1534$.

Zinna, G. (2013). Sovereign default risk premia: Evidence from the default swap market. Journal of Empirical Finance 21, 15 - 35. 
Fig. 1. Unspanned and spanned factors
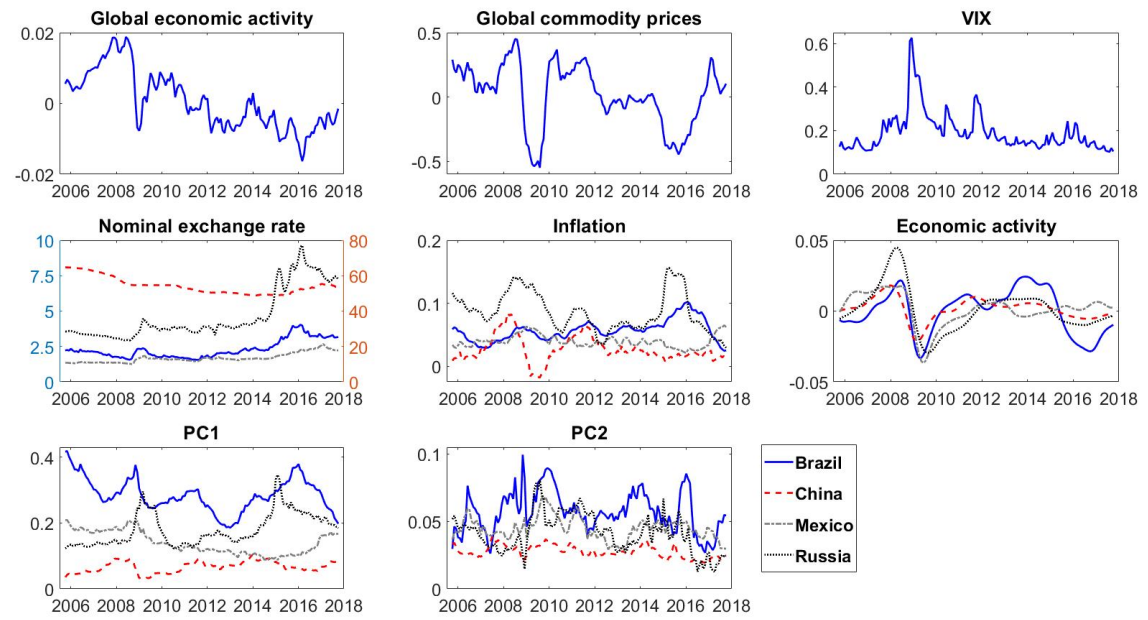

Note: The figure depicts the time series of all eight factors used in the model: $(i)$ Three global unspanned factors. Global economic activity is the Kilian's measure (Kilian, 2009), global commodity prices is the yearly growth of the global commodity price index, and VIX is the CBOE Market Volatility Index. The last two series are from the FRED website; (ii) Three country-specific unspanned factors. The nominal exchange rate is expressed as the price of one US dollar in terms of the local currency (left-hand scale: Brazil and China; right-hand scale: Mexico and Russia), obtained from the IMF. Inflation is the yearly growth rate of each country's CPI, also from the IMF, and domestic economic activity is the normalized countryspecific leading indicator for the GDP developed by the OECD, also retrieved from the FRED website; and (iii) The country-specific spanned factors (PC1 and $P C 2)$, which are the first two principal components of the country's bond yields. All series span from September 2005 to September 2017. 


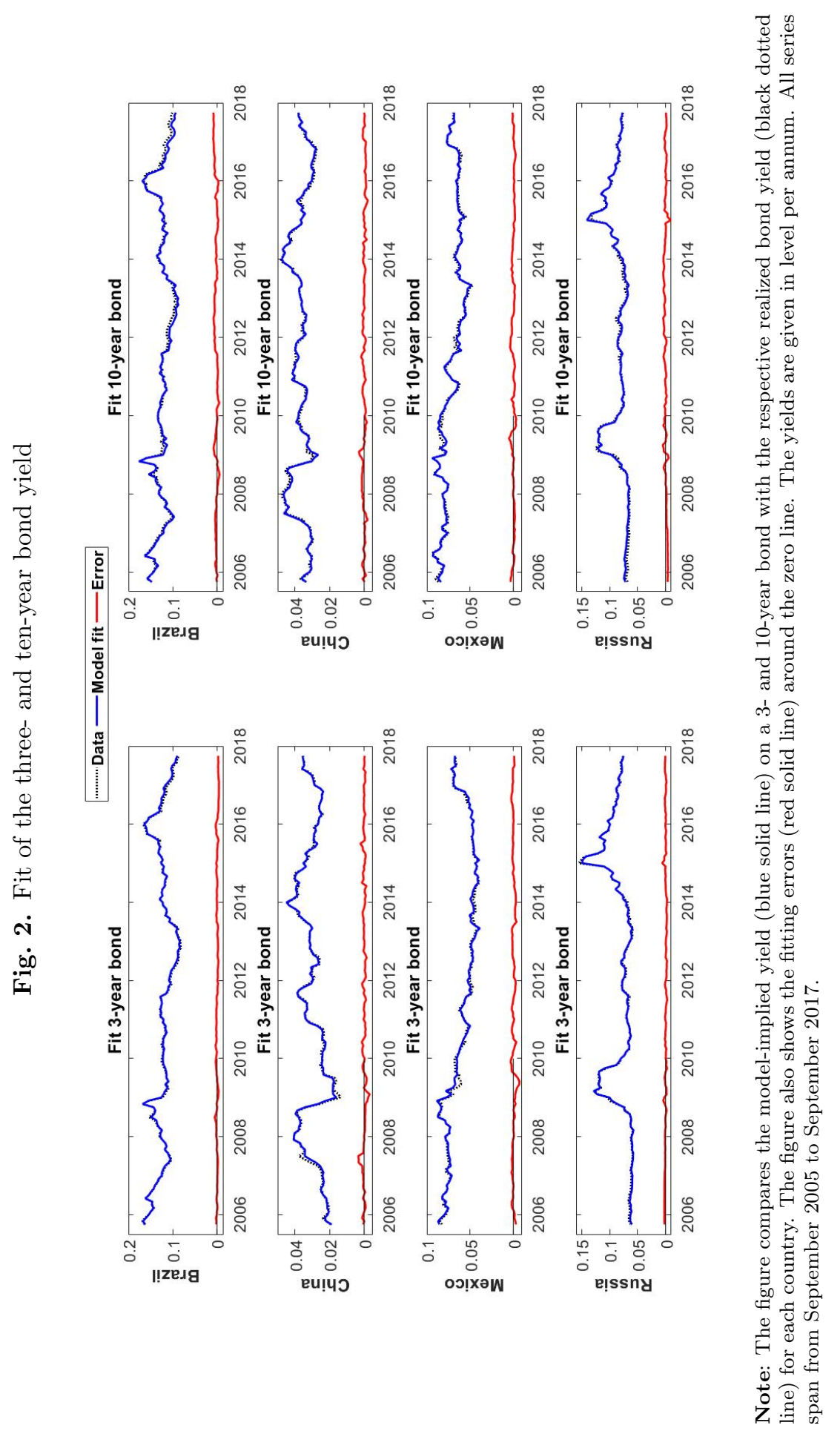




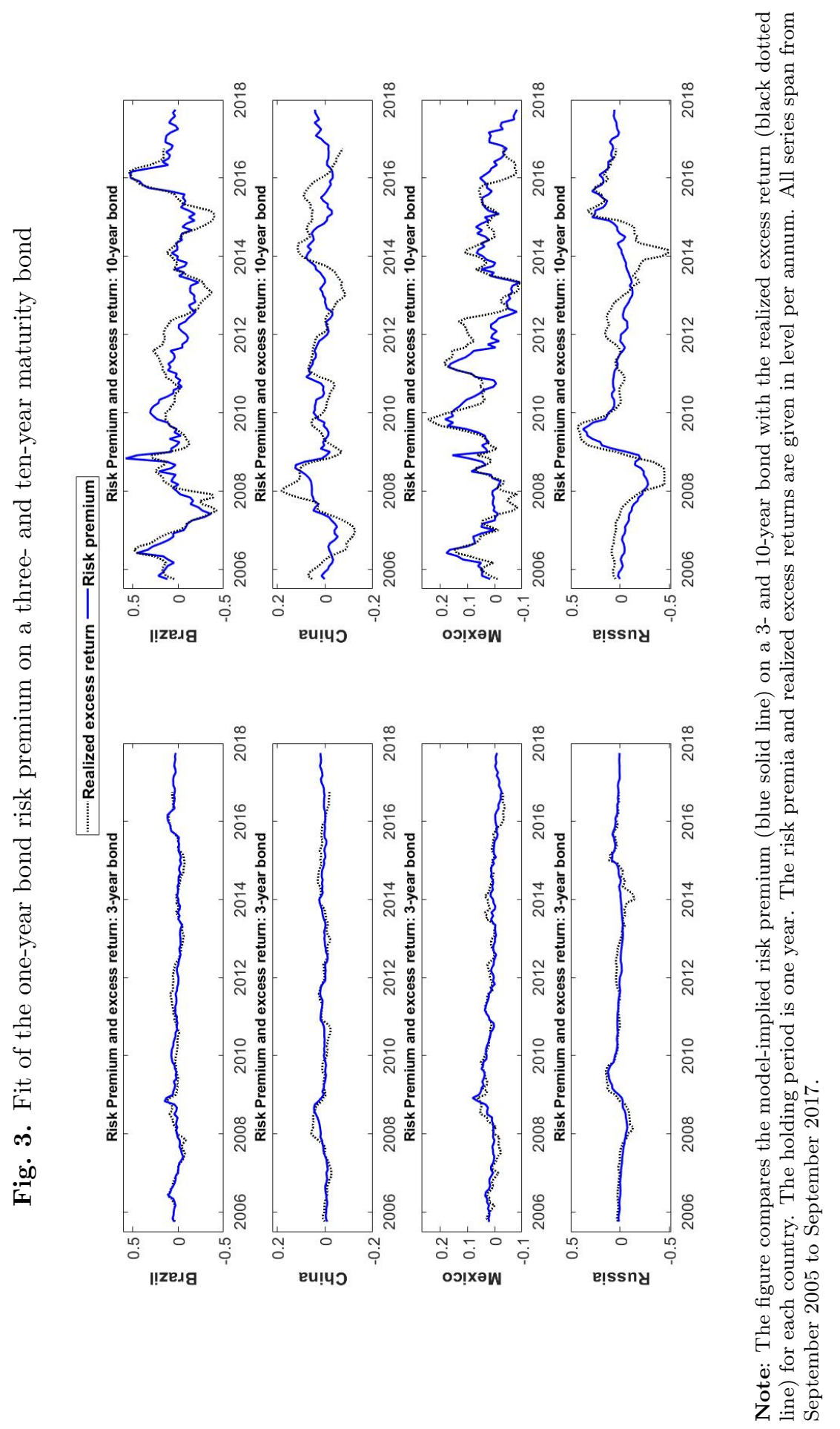




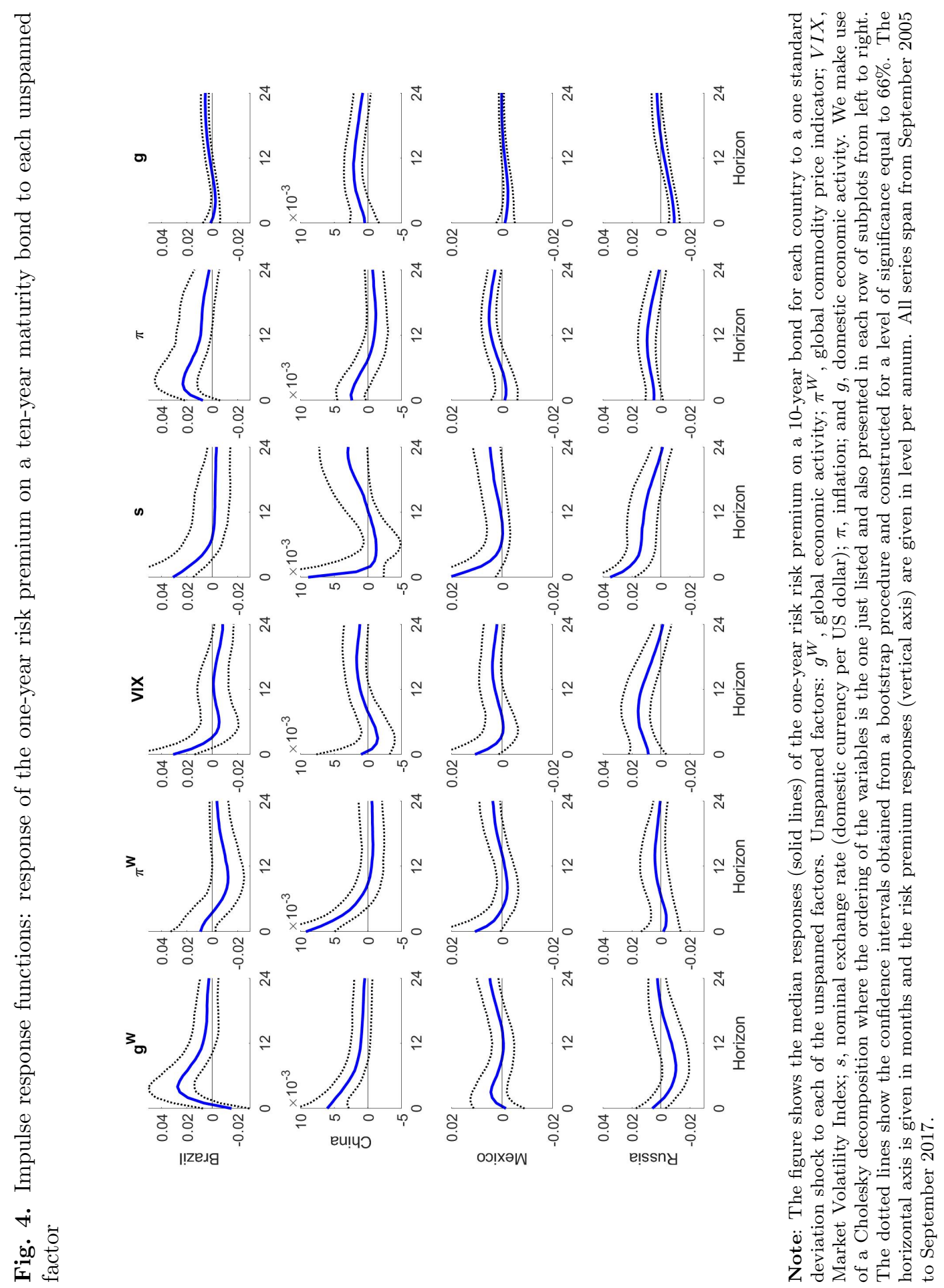




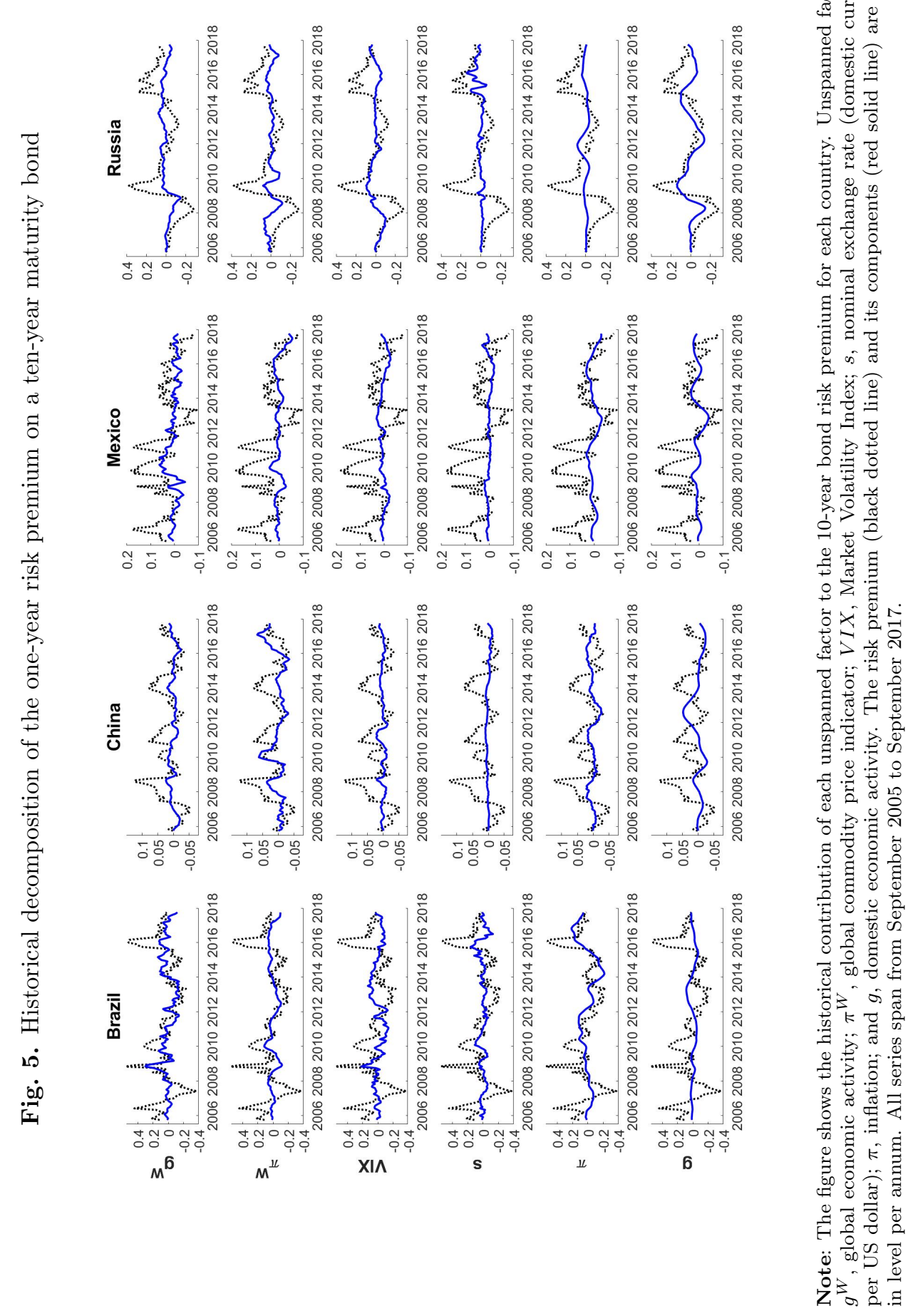




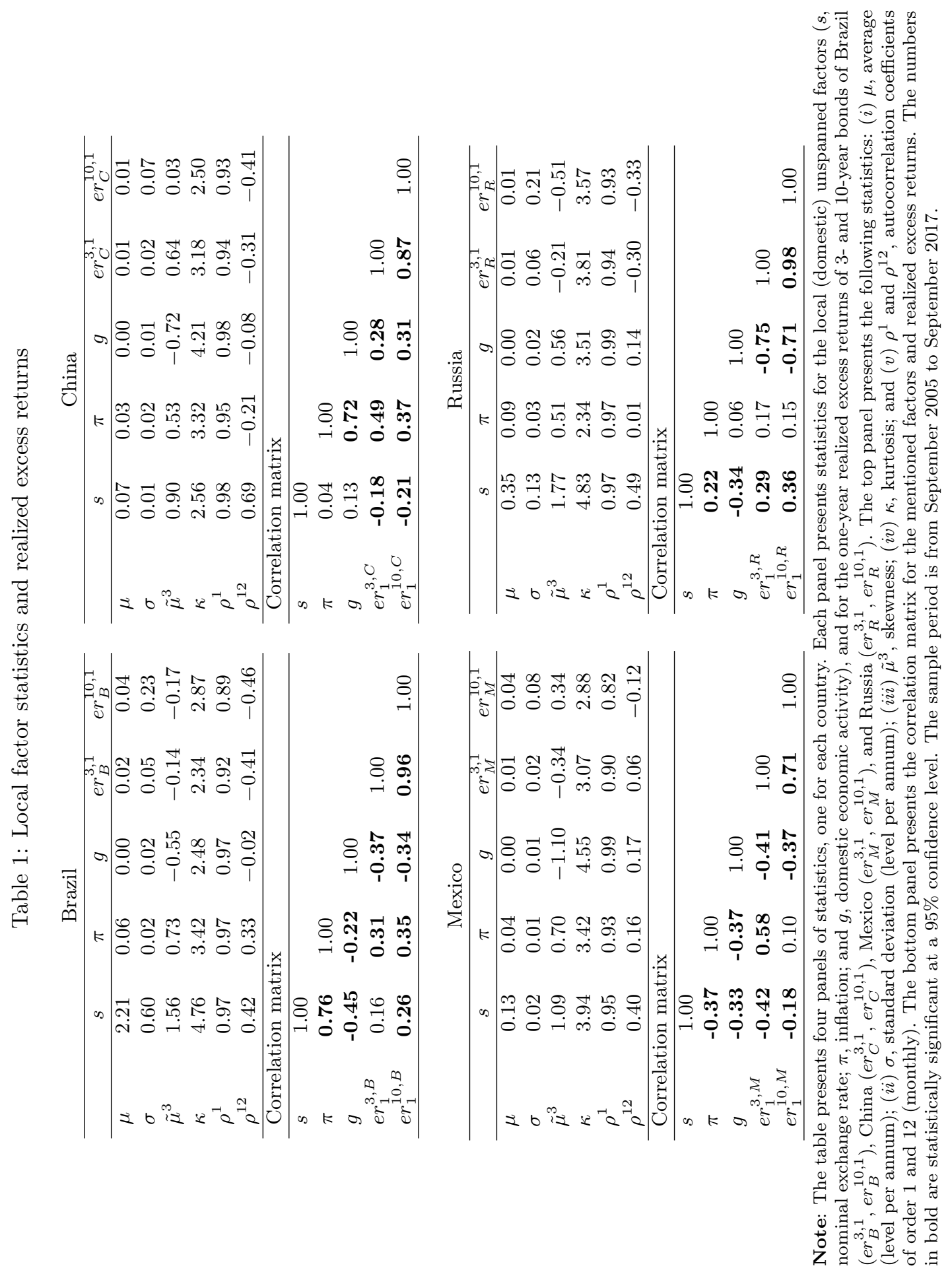




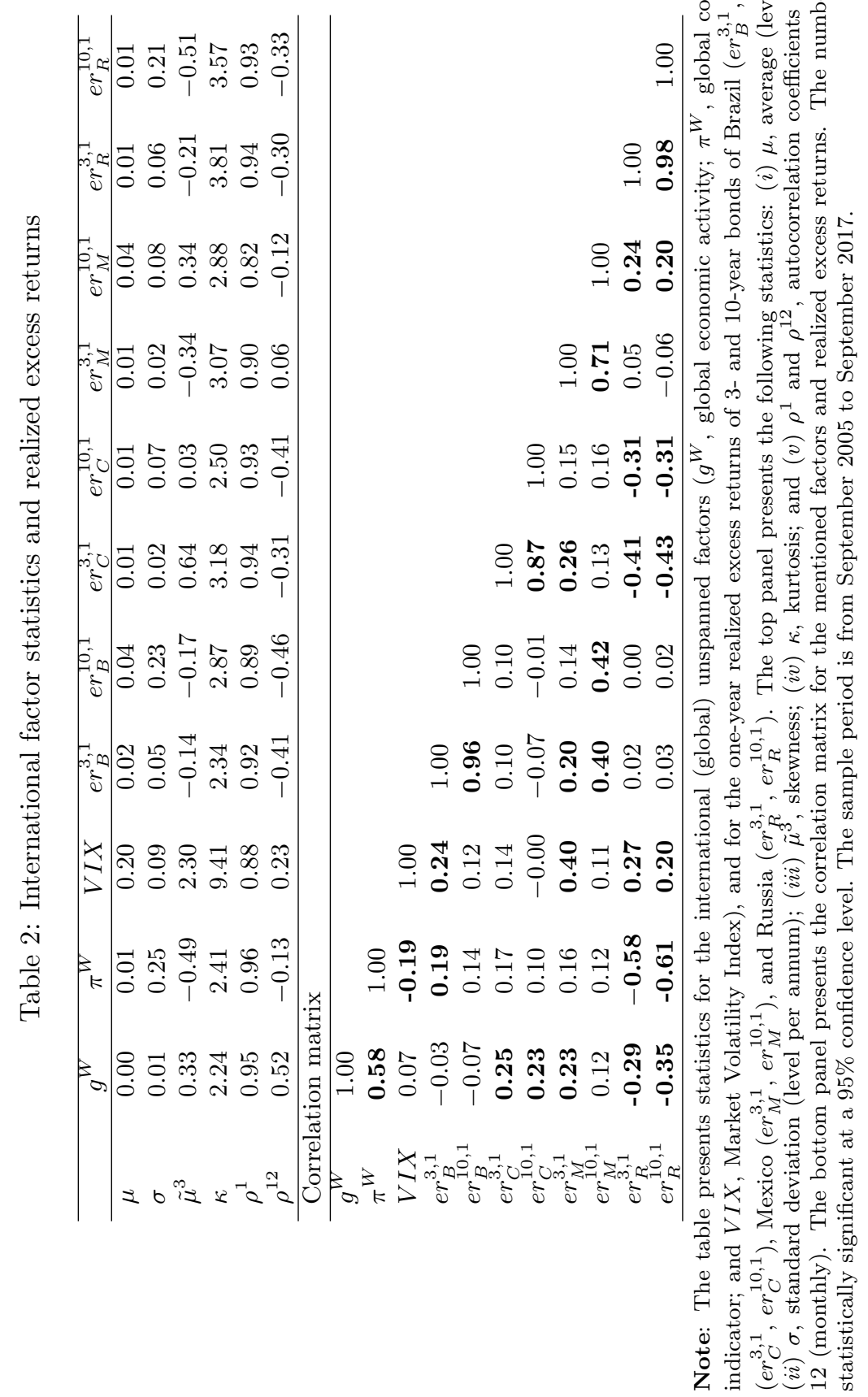


Table 3: Fit of the yield curves

\begin{tabular}{lcccccc}
\hline & \multicolumn{6}{c}{ Bond maturity (month) } \\
\cline { 2 - 7 } Country & 1 & 6 & 12 & 36 & 60 & 120 \\
\hline Brazil & 0.98 & 0.99 & 0.96 & 0.99 & 0.99 & 0.95 \\
China & 0.99 & 1.00 & 0.99 & 0.98 & 0.98 & 0.97 \\
Mexico & 0.99 & 1.00 & 0.99 & 0.98 & 0.99 & 0.98 \\
Russia & 1.00 & 1.00 & 0.99 & 0.99 & 1.00 & 0.98 \\
\hline
\end{tabular}

Note: The table reports the coefficient of determination $\left(R^{2}\right)$ of model-implied bond yields in fitting realized bond yields for each country separately. The sample period is from September 2005 to September 2017. 


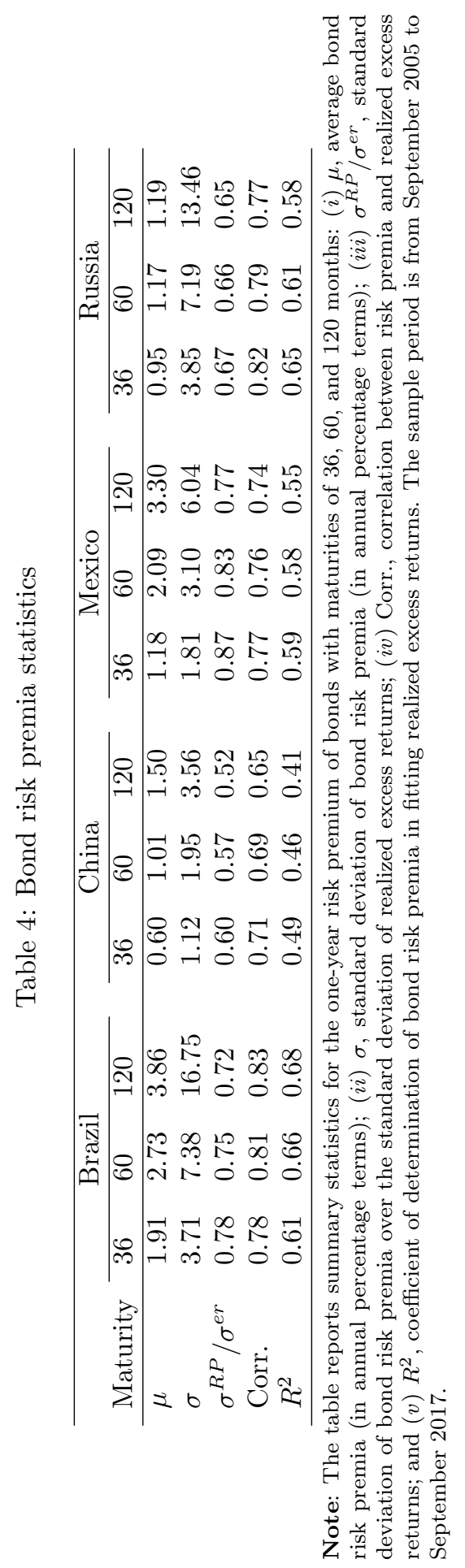


Table 5: Variance decomposition of the one-year risk premium on a ten-year bond

Brazil

\begin{tabular}{|c|c|c|c|c|c|c|c|c|}
\hline $\begin{array}{l}\text { Horizon } \\
\text { (mth) }\end{array}$ & $g^{W}$ & $\pi^{W}$ & $V I X$ & $s$ & $\pi$ & $g$ & $P C 1$ & $P C 2$ \\
\hline 1 & 0.20 & 0.02 & 0.20 & 0.17 & 0.00 & 0.00 & 0.21 & 0.20 \\
\hline 12 & 0.29 & 0.06 & 0.09 & 0.13 & 0.14 & 0.00 & 0.15 & 0.14 \\
\hline 60 & 0.28 & 0.11 & 0.13 & 0.10 & 0.16 & 0.03 & 0.09 & 0.10 \\
\hline 120 & 0.29 & 0.10 & 0.15 & 0.09 & 0.18 & 0.04 & 0.07 & 0.08 \\
\hline \multicolumn{9}{|c|}{ China } \\
\hline $\begin{array}{l}\text { Horizon } \\
(\mathrm{mth})\end{array}$ & $g^{W}$ & $\pi^{W}$ & $V I X$ & $s$ & $\pi$ & $g$ & $P C 1$ & $P C 2$ \\
\hline 1 & 0.05 & 0.23 & 0.05 & 0.01 & 0.06 & 0.00 & 0.16 & 0.44 \\
\hline 12 & 0.12 & 0.19 & 0.07 & 0.02 & 0.05 & 0.02 & 0.07 & 0.46 \\
\hline 60 & 0.10 & 0.20 & 0.08 & 0.02 & 0.07 & 0.06 & 0.06 & 0.41 \\
\hline 120 & 0.10 & 0.20 & 0.08 & 0.02 & 0.07 & 0.06 & 0.06 & 0.41 \\
\hline
\end{tabular}

\begin{tabular}{|c|c|c|c|c|c|c|c|c|}
\hline \multicolumn{9}{|c|}{ Mexico } \\
\hline $\begin{array}{l}\text { Horizon } \\
(\mathrm{mth})\end{array}$ & $g^{W}$ & $\pi^{W}$ & $V I X$ & $s$ & $\pi$ & $g$ & $P C 1$ & $P C 2$ \\
\hline 1 & 0.08 & 0.01 & 0.01 & 0.01 & 0.00 & 0.00 & 0.43 & 0.46 \\
\hline 12 & 0.04 & 0.02 & 0.01 & 0.01 & 0.01 & 0.02 & 0.45 & 0.44 \\
\hline 60 & 0.16 & 0.06 & 0.04 & 0.07 & 0.13 & 0.02 & 0.28 & 0.24 \\
\hline 120 & 0.16 & 0.06 & 0.05 & 0.07 & 0.13 & 0.02 & 0.27 & 0.24 \\
\hline \multicolumn{9}{|c|}{ Russia } \\
\hline $\begin{array}{l}\text { Horizon } \\
\text { (mth) }\end{array}$ & $g^{W}$ & $\pi^{W}$ & $V I X$ & $s$ & $\pi$ & $g$ & $P C 1$ & $P C 2$ \\
\hline 1 & 0.04 & 0.19 & 0.05 & 0.32 & 0.00 & 0.06 & 0.05 & 0.29 \\
\hline 12 & 0.19 & 0.11 & 0.10 & 0.12 & 0.04 & 0.08 & 0.28 & 0.08 \\
\hline 60 & 0.21 & 0.06 & 0.11 & 0.11 & 0.06 & 0.05 & 0.33 & 0.07 \\
\hline 120 & 0.21 & 0.06 & 0.11 & 0.11 & 0.06 & 0.05 & 0.33 & 0.07 \\
\hline
\end{tabular}

Note: The table reports the contribution of each factor to the forecast variance of the oneyear risk premium on a 10-year bond for each country. We use a Cholesky decomposition with the variables ordered from the most exogenous (international factors) to the least exogenous (national factors), as follows. Unspanned factors: $g^{W}$, global economic activity; $\pi^{W}$, global commodity price indicator; $V I X$, Market Volatility Index; $s$, nominal exchange rate (domestic currency per US dollar); $\pi$, inflation; and $g$, domestic economic activity. Spanned factors: $P C 1$ and $P C 2$, first and second principal components of the country's bond yields, respectively. The forecasting horizons considered are 1, 12, 60, and 120 months. Each row in the table, therefore, adds up to $100 \%$. 


\section{A Appendix - Figures and Tables}

Table 6: Variance decomposition of the one-year risk premium on a three-year bond

Brazil

\begin{tabular}{|c|c|c|c|c|c|c|c|c|}
\hline $\begin{array}{l}\text { Horizon } \\
(\mathrm{mth})\end{array}$ & $g^{W}$ & $\pi^{W}$ & $V I X$ & $s$ & $\pi$ & $g$ & $P C 1$ & $P C 2$ \\
\hline 1 & 0.26 & 0.01 & 0.30 & 0.13 & 0.00 & 0.00 & 0.16 & 0.13 \\
\hline 12 & 0.30 & 0.04 & 0.16 & 0.12 & 0.14 & 0.01 & 0.13 & 0.11 \\
\hline 60 & 0.31 & 0.09 & 0.17 & 0.09 & 0.18 & 0.03 & 0.06 & 0.06 \\
\hline 120 & 0.30 & 0.09 & 0.19 & 0.08 & 0.19 & 0.04 & 0.05 & 0.05 \\
\hline \multicolumn{9}{|c|}{ China } \\
\hline $\begin{array}{l}\text { Horizon } \\
(\mathrm{mth})\end{array}$ & $g^{W}$ & $\pi^{W}$ & $V I X$ & $s$ & $\pi$ & $g$ & $P C 1$ & $P C 2$ \\
\hline 1 & 0.08 & 0.08 & 0.02 & 0.00 & 0.23 & 0.04 & 0.54 & 0.02 \\
\hline 12 & 0.14 & 0.16 & 0.14 & 0.01 & 0.22 & 0.03 & 0.18 & 0.12 \\
\hline 60 & 0.11 & 0.17 & 0.13 & 0.01 & 0.22 & 0.08 & 0.15 & 0.14 \\
\hline 120 & 0.11 & 0.17 & 0.13 & 0.01 & 0.22 & 0.08 & 0.15 & 0.14 \\
\hline \multicolumn{9}{|c|}{ Mexico } \\
\hline $\begin{array}{l}\text { Horizon } \\
(\mathrm{mth})\end{array}$ & $g^{W}$ & $\pi^{W}$ & $V I X$ & $s$ & $\pi$ & $g$ & $P C 1$ & $P C 2$ \\
\hline 1 & 0.34 & 0.00 & 0.05 & 0.00 & 0.05 & 0.00 & 0.35 & 0.21 \\
\hline 12 & 0.23 & 0.01 & 0.06 & 0.01 & 0.21 & 0.01 & 0.31 & 0.16 \\
\hline 60 & 0.32 & 0.06 & 0.05 & 0.11 & 0.18 & 0.01 & 0.20 & 0.08 \\
\hline 120 & 0.31 & 0.07 & 0.06 & 0.11 & 0.17 & 0.01 & 0.19 & 0.07 \\
\hline \multicolumn{9}{|c|}{ Russia } \\
\hline $\begin{array}{l}\text { Horizon } \\
\text { (mth) }\end{array}$ & $g^{W}$ & $\pi^{W}$ & $V I X$ & $s$ & $\pi$ & $g$ & $P C 1$ & $P C 2$ \\
\hline 1 & 0.03 & 0.19 & 0.03 & 0.24 & 0.02 & 0.13 & 0.13 & 0.24 \\
\hline 12 & 0.18 & 0.08 & 0.12 & 0.06 & 0.07 & 0.10 & 0.36 & 0.04 \\
\hline 60 & 0.20 & 0.05 & 0.11 & 0.10 & 0.08 & 0.06 & 0.36 & 0.05 \\
\hline 120 & 0.20 & 0.05 & 0.10 & 0.11 & 0.08 & 0.06 & 0.36 & 0.05 \\
\hline
\end{tabular}

Note: The table reports the contribution of each factor to the forecast variance of the oneyear risk premium on a 3-year bond for each country. We use a Cholesky decomposition with the variables ordered from the most exogenous (international factors) to the least exogenous (national factors), as follows. Unspanned factors: $g^{W}$, global economic activity; $\pi^{W}$, global commodity price indicator; VIX, Market Volatility Index; $s$, nominal exchange rate (domestic currency per US dollar); $\pi$, inflation; and $g$, domestic economic activity. Spanned factors: $P C 1$ and $P C 2$, first and second principal components of the country's bond yields, respectively. The forecasting horizons considered are 1, 12, 60, and 120 months. Each row in the table, therefore, adds up to $100 \%$. 


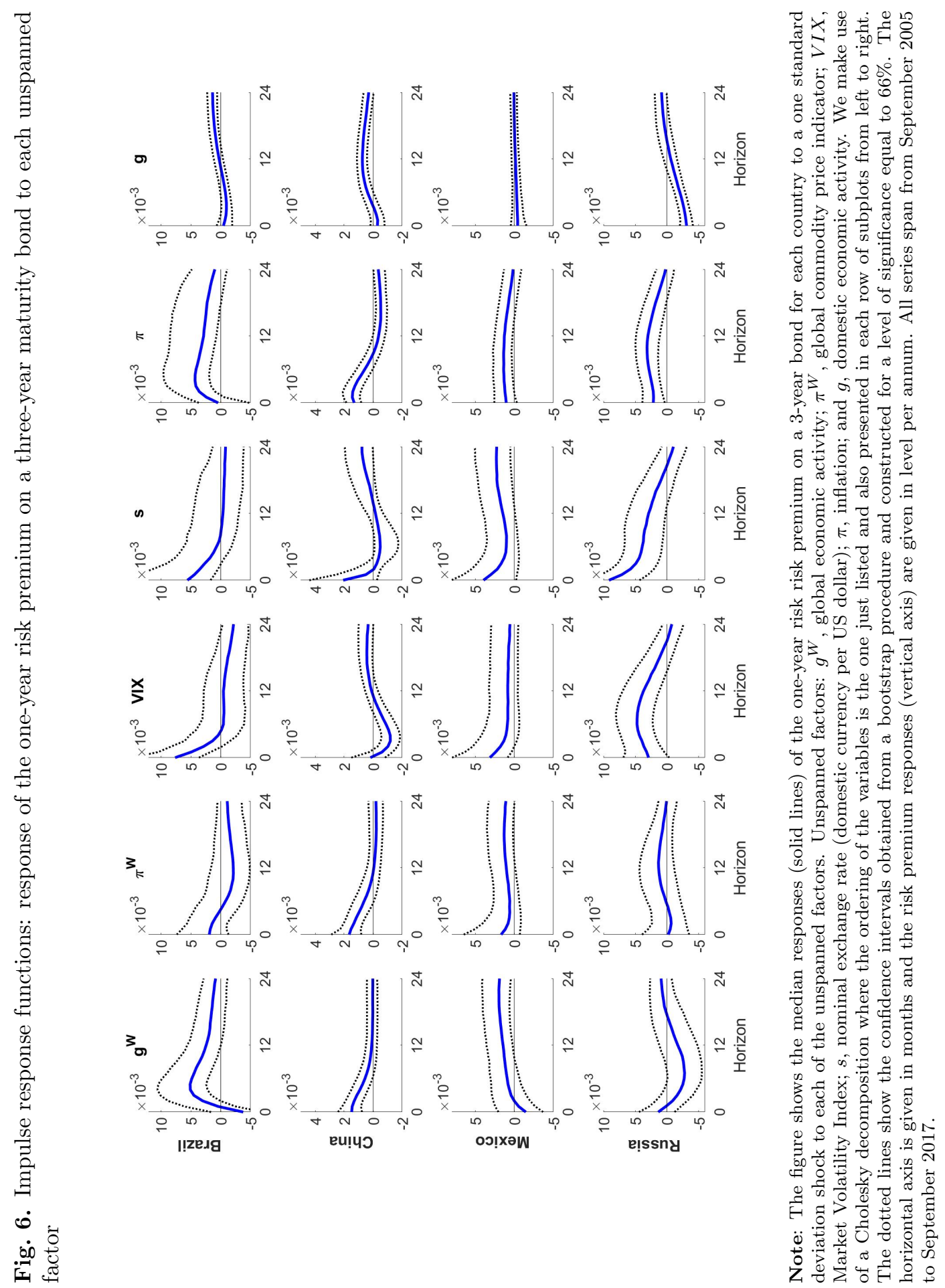




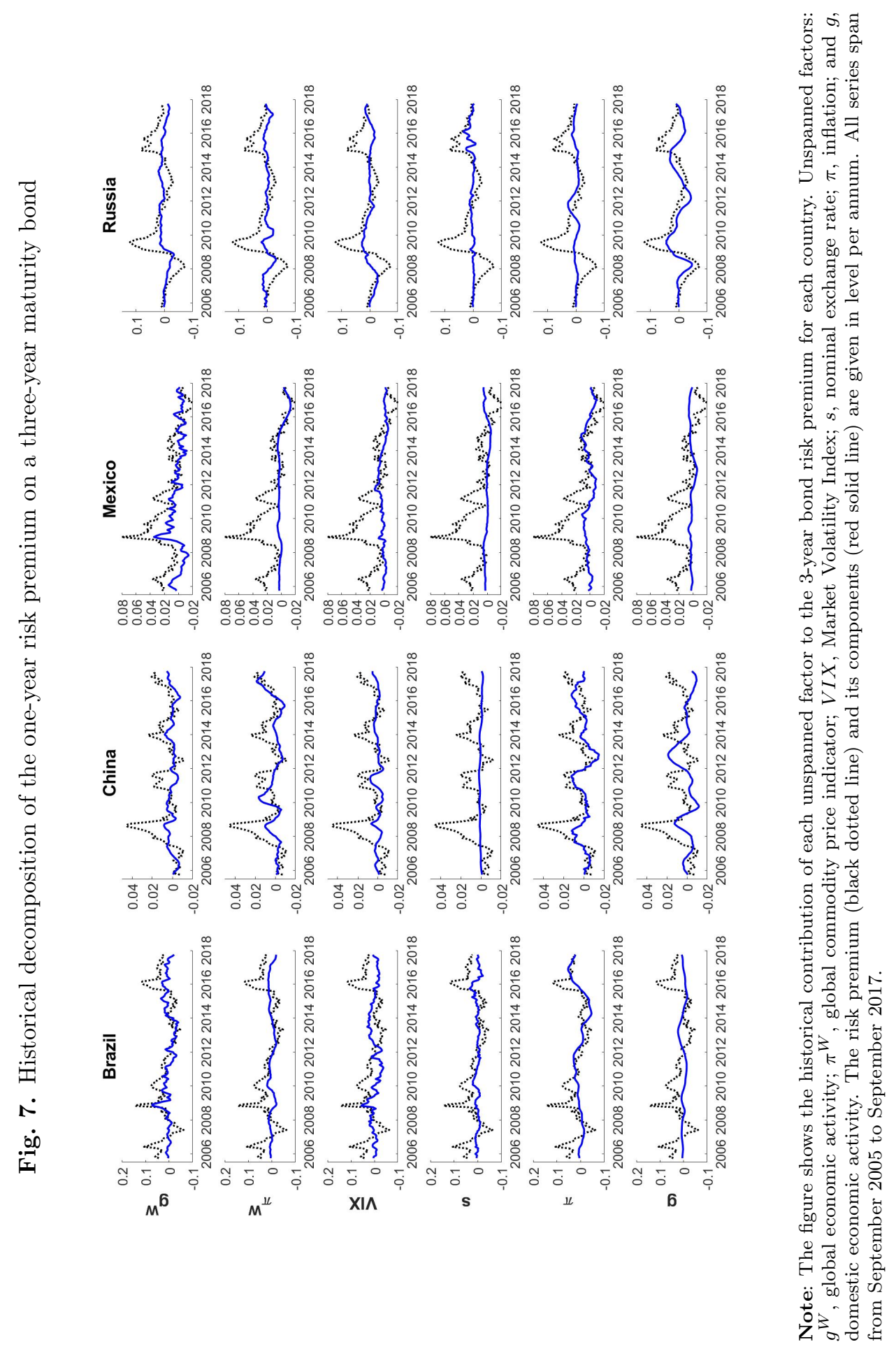

